\title{
Challenges in Systemic Education Reform
}

Susan H. Fuhrman

Follow this and additional works at: https://repository.upenn.edu/cpre_policybriefs

Part of the Curriculum and Instruction Commons, and the Education Policy Commons

\section{Recommended Citation}

Fuhrman, Susan H.. (1994). Challenges in Systemic Education Reform. CPRE Policy Briefs.

Retrieved from https://repository.upenn.edu/cpre_policybriefs/72

View on the CPRE website.

This paper is posted at ScholarlyCommons. https://repository.upenn.edu/cpre_policybriefs/72

For more information, please contact repository@pobox.upenn.edu. 


\title{
Challenges in Systemic Education Reform
}

\author{
Abstract \\ Reform is generating a great deal of excitement and energy is associated with many positive classroom \\ changes. But policymakers and educators are also facing a number of challenges in designing and \\ implementing the new policies. This policy brief examines these challenges as well as strategies states \\ are using to address them. It draws from CPRE's studies of reform in 19 states and from discussions with \\ staff of policymaker associations involved in providing assistance to states. \\ Disciplines \\ Curriculum and Instruction | Education Policy \\ Comments \\ View on the CPRE website.
}




\title{
Challenges in Systemic Education Reform
}

\author{
by Susan $H$. Fuhrman
}

By mid-1994, many states claimed to be developing challenging expectations for student learning and coordinating other policies so they support the expectations. ${ }^{1}$ The Clinton Administration was preparing to grant states and localities support for such activities as part of its Goals 2000 program. The reform movement, labelled "systemic" or "standardsbased" reform, though new, is so prevalent that it is already possible to study and contrast a variety of approaches.

Reform is generating a great deal of excitement and energy and is associated with many positive classroom changes. ${ }^{2}$ But policymakers and educators are also facing a number of challenges in designing and implementing the new policies. This issue of $C P R E$ Policy Briefs examines these challenges as well as strategies states are using to address them. It draws from CPRE's studies of reform in 19 states and from discussions with staff of policymaker associations involved in providing assistance to states. ${ }^{3}$

\section{Variation in State Approaches}

State approaches to reform vary in several ways. While state and local leadership frequently operate in tandem (Fuhrman and Elmore 1990), some systemic reform efforts show clear state direction while others rely more on local initiative. Two varieties of state leadership may be seen in Kentucky, where legislation spelled out all components of a comprehensive plan, and Vermont, where reform elements are being integrated by leaders, educators and others involved in the process, but are not laid out in blueprint fashion. A more local approach is evident in Florida, where standardsetting and assessment of progress has been deliberately transferred to local districts. Local direction may also come about unintentionally. In New Jersey, leadership changes stalled state-directed efforts to create content standards and curriculum frameworks, leaving it up to local districts to pursue their own strategies, like conforming math curricula to NCTM standards or participating in the National Science Foundation's Statewide Systemic Initiatives (SSI) projects.

States also vary in the policy instrument they stress in systemic reform efforts. In California, the lead instruments are subject-area frameworks setting out expectations for student learning. They have been the basis for materials adoption, professional development activity and attempts to improve teacher education. Only after ten years of this process did the state institute performance-based student assessments, matched to the frameworks. Connecticut, having pioneered development of performance-based tasks, relies on assessment and on attracting high quality teachers. Most other states stress assess-

Susan H. Fuhrman is professor of educational policy at Rutgers, The State University of New Jersey. She also serves as director of the Consortium for Policy Research in Education.

Dr. Fuhrman is the author of numerous articles, research reports, and monographs on education policy and finance. Dr. Fuhrman was a consultant to the Ford Foundation's program on educational management and finance for 10 years and served as vice-president of the school board in Westfield, New Jersey. 
ments, some intentionally and some not. Georgia,which has a new assessment system and very few other instructional reforms, and Michigan, which has revised its MEAP assessment for selected grades and is now developing a new high school test, placed testing first. States like Kentucky and Delaware, with their comprehensive reform strategies, did not single out assessment, but because interim assessments preceded frameworks and other reform elements - and attracted a great deal of attention-assessments have become their leading strategies, as well.

State experience differs in part simply because some have been in the reform business far longer than others. In California, which has been working at these reforms for over a decade, a considerable amount of policy integration has been achieved, and many observers report that teachers are trying to change their practice as a result (Cohen 1990; Cohen and Ball 1990). Other states, like Kentucky and Vermont, are three or four years into reform, and are also beginning to look for classroom effects, related, for example, to Kentucky's ungraded primary program and to Vermont's portfolio assessments. Still others, like New Jersey, have just started.

Finally, states vary in their capacity to marshal technical and policy expertise to carry out high quality, well-designed reforms. While virtually all state education agencies and many local district offices have experienced cuts during the recent recession, some have suffered more than others. States also differ in the number, quality and cooperativeness of potential outside sources of assistance, such as universities, foundations, networks, associations and other nonprofits. To build capacity for reform, some states, like California, have relied both on strong state agency leadership and a variety of orchestrated networks; in others, like Vermont, agency leadership has created outside capacity by generating networks of professionals working on various development tasks. In Michigan, strong universities and professional associations have provided leadership.

\section{Difficulties in Accomplishing the Reform Agenda}

CPRE research shows that state and local policymakers are confronting a number of difficulties in attempting to carry out elements of the reform agenda.

\section{Overwhelming Work Load; Limited Resources}

Current policy activity is complex and extremely demanding. States are designing and developing new processes, structures and substantive policy initiatives across a broad range of policy areas. Policymakers are working on standards-based reforms in $\mathrm{K}-12$ education at the same time they are expanding preschool programs, experimenting with integrated social services and embarking on school-to-work transition efforts. Most are hoping to undertake these reforms not just simultaneously, but in an integrated way. The result is a very high level of activity as well as a need to coordinate activities of bodies-like professional standards boards, state boards of education and higher education governance bodies and institutions-deliberately designed to operate independently.

The recent round of recessionrelated budget cuts at both state and local levels has compounded the problem, reducing staff and discretionary resources for planning, development and public and professional involvement. Often the greatest staff losses occurred among those with the most expertise related to current reforms-subject-matter experts and policy generalists on general fund support.

Mounting workloads and reduced resources have hurt reform efforts in several ways. Confusion, bordering on chaos, is evident in states where various bodies go on meeting independently and then have to go over the same ground again when they find out what others have done; where high school and elementary school tests are developed separately without assurance of compatibility; or where standards bodies develop frameworks that overwhelm students and teachers. In some states, scarcity of resources is reflected in allocation of too little time or money for assessment development, despite the centrality of performance assessment to the entire reform enterprise.

Some states are experiencing serious sequencing difficulties as various elements of reform run on different schedules. Some have new content expectations but old, norm-referenced, standardized tests that do not assess the knowledge and skills now expected of students. Florida's math and science efforts, for example, are based on emerging national standards, but the state has removed all statewide testing, leaving local districts to rely for the most part on commercially published tests. New Jersey planned to develop new fourthgrade tests to reflect the state's new content standards, but put the process on hold in the wake of budget problems and leadership changes. 
A different sequencing problem arises in states that have new tests, but may not have given teachers and students adequate opportunity to learn the new material. In Georgia, the use of a new high school graduation test as a gate had to be postponed because students were not prepared. In Kentucky, interim assessmentsconsiderably more demanding than prior tests-are in place, but it is unlikely that sufficient instructional changes have occurred at the grades tested. The curriculum framework has just been published, no materials or specific curricula exist and, because of the reform act's emphasis on ungraded primary schools, professional development has focused mostly on early grades that are not subject to assessment.

Yet another sequencing problem occurs when new tests are used before they are technically sound. Of course these problems are much more serious and visible when there are high stakes attached to the testing.

\section{Articulating the Nature and Intent of Reforms}

Many policymakers, educators and analysts are having problems explaining the role of coherent, standards-based policy in providing direction and support for changes in teaching and learning. In policy rhetoric, it frequently appears that reforms consist only of standards and assessments. Other central components, like support for classroom change through focused and enhanced teacher education and professional development, are less visible. The broader social agenda, like providing for children's health and security, also gets short-changed in reform discussions. Public skepticism is understandable in reaction to messages suggesting that setting standards and measuring achievement, in and of themselves, can somehow lead to better teaching and learning.

In states such as Connecticut, public confusion is expressed as concern that common standards may mean lower standards. Many urban and rural educators and parents worry that the standards discussion means new rules without new solutions to persistent problems of poverty. In Ohio, Pennsylvania, Kentucky, Virginia, and other states, confusion has also fueled virulent opposition to outcomes-based education, a version of standards reform that frequently includes affective outcomes as well as academic standards.

\section{Going Beyond Standards and Assessments}

Since reformers are having trouble conceptualizing the full extent of required changes, it is not surprising that strategies for effecting change are lacking. Once processes for standards and assessments are in place, it is not clear what to do next, and few strategies exist for encouraging real change in practice. Filling the gap between standards and assessments at one end and changed practice at the other requires significant action in a number of areas, including many in which policy has traditionally been weak.

- Incentives. Policymakers have traditionally equated monetary incentives with payments to encourage local participation in various programs, a concept that has little to do with results of schooling. But recently, some states are beginning to experiment with sizable monetary rewards for performance. Kentucky will begin distributing as much as $\$ 3200$ per teacher to schools where performance ex- ceeds targets, and the Dallas Independent School District has just implemented a complex system to reward schools for higher than predicted gains. Also remaining to be explored are a variety of non-monetary incentives such as improving professional opportunities for learning, discretionary action and selfregulation. New governance approaches, like choice and charters, can alter non-monetary incentives.

In Minnesota there is evidence that choice enhances interest in standards-based reforms, and schools are competing with one another to improve their curricula and assessment strategies. Of course, another way to increase incentives is to remove current disincentives to change, like finance formulas, program regulations or union contract provisions that lock schools into certain staffing ratios and organizational patterns.

- Professional Development. Increasingly, reformers are recognizing that traditional staff development-one-shot workshops designed to deliver prepackaged knowledge-is incompatible with current reforms (Little 1993). To achieve marked improvements in classrooms, professional development must be continuous and embedded in practice. Teachers and administrators need many, varied opportunities to make sense of new policies and to reconstruct practice in light of new expectations and new knowledge about teaching and learning. While new formats, such as networks and collaboratives, are emerging, little progress has been made in designing policies-like revised approaches to certification, compensation or instructional time-that would support such formats and give teachers time to participate on a continuing basis. 
- Accountability. Most states say they are moving toward more performance-based accountability, focusing on reporting curriculum-aligned test scores or gains at several grade levels and on periodic accreditation reviews that center on outcomes. Many are attaching rewards, such as deregulation, and sanctions, such as peer assistance and eventual state displacement of local leadership, to outcome or valueadded measures. However, states are finding it difficult to move to performance-based systems for a number of reasons, such as the slow development of good and widely accepted outcome measures.

Policymakers are also finding it difficult to remove regulations about inputs and processes or to limit the extent to which accreditation/certification reviews focus on compliance with such regulations. Regulations protect politically powerful groups, like categorical program providers and specialty teachers, and particularly needy constituencies, like disadvantaged children. States have historically seen protection of students and assurance of minimum quality as the cornerstones of their role in education and are reluctant to abandon input and process regulations designed to guarantee equitable services (Elmore and Fuhrman 1994).

A major dilemma in the design of new accountability systems is fashioning interventions that really improve instruction in lowperforming schools and districts. States need to distinguish compliance-driven sanctions, designed for corrupt or mismanaged localities, from improvement strategies designed to influence classrooms in low-achieving schools.

- Scaling up. In many states, standards-based systemic reform efforts can be found in geographic pockets, such as pilot sites, or at certain grade levels, or in certain subject areas. A key challenge is generalizing these approaches, especially since moving from good examples to more widespread reform has been a traditional weakness of education policy. In a number of states, technical and policy efforts appear to run on separate tracks. Some excellent pilots, in professional development, for example, exist in states that have not developed policies to support such efforts on a broader scale, while other states have policies in place, but lack high quality interventions worth generalizing.

These examples concern just some of the areas where imagination and new approaches are needed. Despite growing awareness that these areas need work, they typically appear on policymakers' agendas simply as categories where efforts are necessary. Coming up with strategies to accomplish and integrate change in these areas is much harder.

\section{Equity}

Making equity a central reform thrust is proving to be a major challenge for states and equity is continuing to get less attention than it should. Many states include only token representation of special needs programs in standards reform, pay insufficient attention to achievement gaps on new tests and fail to provide extra resources and assistance special needs schools must have if reforms are to succeed. Standards-based systemic reform has equity at its philosophical core. It is based, after all, on the notions that all students can learn to much higher levels and that high common standards can help reverse the tradition of advantaged schools aiming high and less advantaged schools getting left behind (Smith and O'Day
1991; O'Day and Smith 1993). Indeed, policymakers use equity arguments in promoting the reforms. Congressional debates on opportunity-to-learn standards in Goals 2000 and on reauthorization of the Elementary and Secondary Education Act suggest that equity has relatively high visibility in standards discussions within the Beltway. Its relative lack of visibility in the states is therefore a surprise as well as a disappointment.

\section{Competing Problems}

Other problems and issues sometimes tend to overshadow systemic reform efforts. Local educators frequently mention crime, not education reform, as their greatest concern. In most states, desegregation is seen as a separate issue; to our knowledge, only Delaware has tried to tie standards-based reforms to desegregation. Although school finance litigation served as an opportunity for broader reform in Kentucky and Alabama, school finance has been more of a distraction in many states. This is certainly true in New Jersey and Texas where legislative preoccupation with finance has precluded other activity. In states such as South Carolina, Wisconsin and Pennsylvania, proposals to drop the local property tax for schools might detract attention from substantive reform to some extent. It can also be argued that, in certain fast-growing states like California and Texas, where demands are simply overwhelming resources, relatively low spending is a hindrance to reform.

\section{The Grip of the Past}

Despite the energy going into reforms, old ways of doing business persist. Many states still have all or most of their old policies on the books. In Ohio, for example, a ninth grade minimum competency test is just 
going into effect, after years of development and piloting, just as the state is moving toward a focus on higher-order skills. California, the state engaged in standards-based systemic reforms over the longest period, still has its hodgepodge of unrelated categoricals that promote various innovations and experiments. Schools, too, continue to act in familiar ways. For example, they zealously adopt model lessonsintended to provide examples of how standards might be addressed-as if they were required.

\section{Leadership}

The magnitude of the problems that states are encountering highlights the importance of leadership in reform efforts. Skillful guidance can steer reforms through difficult technical and political straits, but sudden or frequent shifts in leadership can be damaging. Of nine states that CPRE has followed since 1990 , five have lost their chief state school officers over the last two years. Virtually all the state agencies in states CPRE has studied have reorganized, mostly into teams aimed at enhancing technical assistance to schools and districts, but this has also occurred under conditions of shrinking agency resources. From the local perspective, state agency reorganization has meant confusing desk-shuffling and inability to obtain information, even the most basic statistics. Most agencies-sectioned into offices corresponding to federal and other special programsweren't well suited to lead reforms to begin with. Reorganization does not yet seem to be improving agency ability to provide leadership in a systemic fashion. It will take time and sustained staff development to build the capacity for coordinated leadership from these agencies.

\section{Strategies to Address The Challenges}

Despite the problems, the energy and excitement surrounding reform is notable. Teachers in Vermont, Kentucky and other states speak enthusiastically about trying to change their practice. In many states, hundreds of citizens have been involved in reform activities. Some current reform efforts, such as curriculum framework commissions, involve many more members of professional associations and of the public than any past educational policy activity in memory. Strategies that generate such energy and involvement are worth studying and emulating.

\section{Building Capacity in New Ways}

As mentioned previously, hardpressed state agencies are finding new ways of creating capacity by extending activities into networks, collaboratives and new bodies. Because they involve so many people, these new structures also serve to broaden participation in design and development efforts and to popularize and promote reform.

In a number of SSI states, new quasi- or non-governmental organizations are playing key leadership roles. Some of these, like the Kentucky Science and Technology Council and the Montana Council of Teachers of Mathematics, are not new organizations, but they are taking on new responsibilities. Others, such as the Council for the Advancement of Mathematics and Science Education in New Mexico and the Connecticut Academy for Education in Science, Mathematics and Technology are new broad-based collaboratives created to promote and extend reform. Such organizations are of particular interest because of their unique relationship to the formal decision-making hierarchy in education and because participants say that they broaden support for reform, particularly among teachers and business leaders (Shields et al. 1993).

Another encouraging sign is the development of school-level reform networks that unite volunteer schools in collaborative efforts to improve professional development and practice. Network membership enhances motivation for change through support, recognition and increased access to knowledge. It also provides a mechanism for spreading effective approaches. Some networks, like the elementary, middle and secondary school collaboratives organized by the California State Department of Education, are explicitly tied to state standardsbased reforms.

\section{Expanding the Meaning of Professional Development}

A related strategy may be emerging as the concept of professional development broadens to include other key reform tasks. Professional development occurs through the development of standards and assessments in states such as Vermont where teachers are key actors in creating curriculum frameworks and designing and scoring portfolio assessments. Professional development is also a central purpose of new peer quality-review efforts, such as those in New York, and California. These reviews also address incentive issues-by creating opportunities for observing and reflecting on practice-and provide a self-regulation component for new accountability approaches. By enlisting teachers to perform essential reform tasks, states benefit from professional expertise, expand resources for reform and provide meaningful 
staff development-all at the same time.

\section{Taking Sufficient Time}

Policymakers are generally quick to press for results, but states that are making progress on reform have taken longer than originally planned, if necessary, to assure quality and widespread participation. Achieving extensive participation in development and refinement of Vermont's Common Core of Learning, for example, took a number of years, time many feel was worthwhile to achieve commitment. Similarly, Connecticut's new performance-based assessment tasks have been piloted for much longer than anticipated. As a result, teachers are more comfortable than they would have been otherwise.

\section{Being Honest}

Since the idea of societal agreement on student expectations is at the core of the current reform movement, the public's role is key. States have found that "going public" about the challenges of reform, including specific problems, is as helpful as strategies to assure public participation. Open, truthful exchange of information with the publicsuch as Vermont's release and forthright response to the RAND Corporation's report of problems in the portfolio assessment program-can enhance understanding and reinforce a cooperative approach to problem solving.

\section{Taking Advantage of the National, Secular Trend}

As important as policy changes can be in setting direction for and supporting school-level reform, changes in teaching and learning can find encouragement in many quarters. Fortunately, support for reform is widespread and multifaceted. In states like
Georgia and New Jersey, where there is little state direction for reform, NSF's Statewide Systemic Initiatives is providing important leadership. Publishers are beginning to use emerging standards to guide textbook and test development; national reform networks and collaboratives involve thousands of schools, hundreds of districts, and dozens of states in efforts to improve teaching and learning.

These various reform initiatives may require special efforts aimed at integration. Unless policymakers coordinate various funds associated with federal programs such as SSI, ESEA (Elementary and Secondary Education Act) and the Goals 2000: Educate America Act, for example, these programs are likely to run on parallel tracks that don't aggregate or intersect in helpful ways. But the existence of so many efforts-professional and lay, public and private, school-based and teacher-based-sending the same message about high expectations for all students, provides a reinforcing environment that policymakers can take advantage of. The general trend toward high standards and related conceptions of teaching and learning is an enormously important influence on practice.

Standards-based systemic reform of education is proving to be a demanding challenge. It requires fashioning processes to develop and implement reform; creating technical capacity; building public, political and professional support; designing policy capable of promoting and integrating complex reform components; providing adequate financial resources; and conducting sophisticated research. Analysis of state activity shows that some states have embraced only a fraction of the reform agenda. Some have attempted more and experienced discouraging setbacks. Others are beginning to overcome obstacles and demonstrate real successes that hold promise for transforming their educational systems. The states are providing examples that will benefit policymakers throughout the country as they grapple with the challenges of systemic reform.

\section{Endnotes}

1. By 1994, 45 states claimed to be developing challenging standards and assessments see Pechman, E. and LaGuarda, K. (1993). Status of New Curriculum Frameworks, Standards, Assessments, and Monitoring Systems. Washington, DC: Policy Studies Associates, Inc.

2. Ball, D. L., D. K. Cohen, P. L. Peterson, and S. M. Wilson. (1994). "Understanding State Efforts to Reform Teaching and Learning: The Progress of Instructional Reform in Schools for Disadvantaged Children." Papers presented at The American Educational Research Association's 1994 Annual Meeting in New Orleans, LA.

3. Representatives from the following organizations met with CPRE staff and researchers at the CPRE State Debriefing Meeting, February 1994. Their help is gratefully acknowledged.

Association for Supervision and Curriculum Development

Council of Chief State School Officers

Education Commission of the States

National Conference of State Legislatures

National Governors' Association

National Association of State Boards of Education

U. S. Department of Education

\section{References}

Ball, D., D. K. Cohen, P. L. Peterson, and S. M. Wilson. 1994. "Understanding State Efforts to Reform Teaching and Learning: The Progress of Instructional Reform in Schools for Disadvantaged Children." Papers presented at The American Educa- 
tional Research Association's 1994 Annual Meeting in New Orleans, LA.

Cohen, D. K. 1990. "Revolution in One Classroom: The Case of Mrs. Oublier." Educational Evaluation and Policy Analysis, 12(3), 311-330.

Cohen, D. K., and Ball, D. L. 1990. "Relations Between Policy and Practice: A Commentary." Educational Evaluation and Policy A nalysis, 12(3), 331-338.

Elmore, R. F., and S. H. Fuhrman. 1994. "Opportunity to Learn and the State Role in Education." In The Debate on Opportunity to Learn Standards: Supporting Works. Washington, DC: National Governor's Association.
Fuhrman, S. H., and R. F. Elmore. 1990. "Understanding Local Control in the Wake of State Education Reform." Educational Evaluation and Policy A nalysis, 12(1), 82-96.

Little, J. W. 1993. "Teacher Professional Development in a Climate of Educational Reform." Educational Evaluation and Policy A nalysis 15 (No. 2):129-151.

O'Day, J., and M. S. Smith. 1993. "Systemic School Reform and Educational Opportunity." In Designing Coherent Education Policy: Improving the System, edited by S. H. Fuhrman, 313322. San Francisco: Jossey-Bass.
Pechman, E. and LaGuarda, K. 1993. Status of New Curriculum Frameworks, Standards, Assessments, and Monitoring Systems. Washington, DC: Policy Studies Associates, Inc.

Shields, P. M., T. B. Corcoran, and A. A. Zucker. 1993. The Study of NSF's Statewide Systemic Initatives (SSI) Program: First-Year Report. Menlo Park, CA: SRI International.

Smith, M. S., and J. O'Day. 1991. "Systemic School Reform." In S. Fuhrman and B. Malen, eds., The Politics of Curriculum and Testing, pp. 233-267. Bristol, PA: Falmer Press.

\section{New from CPRE}

\section{Measuring Classroom Practice: Lessons Learned from Efforts to Describe the Enacted Curriculum}

John L. Smithson and Andrew C. Porter

September 1994, 25 pp. (No. RR-031) \$10

This paper addresses issues surrounding attempts to describe instructional practices and learning opportunities. It draws from a study conducted by CPRE for the National Science Foundation-The Reform Up Close Study. The study examined the effects of state and district attempts to increase high school graduation requirements and other standard-setting activities in math and science. The paper focuses on the instrumentation used, the usefulness of the resulting classroom descriptions, and the quality of such data as determined by corroborative evidence.

\section{Merit Aid: Students, Institutions, and Society}

Michael S. McPherson and Morton Owen Schapiro August 1994, 25 pp. (No. RR-030) \$10

This paper draws on recent data sets to pursue answers to several critical questions: What kinds of institutions invest in merit aid? What kinds of students are likely to receive merit aid? How has the level and distribution of merit aid been changing over time? Behind these essentially descriptive questions lies an important policy question: What are the consequences of merit aid practices for the quality and distribution of educational opportunity in the United States? 